\title{
Design industrial na Whirlpool Latin America: filosofia e resultados
}

Fernando Pereira Pruner (Currículo Lattes)

\section{INTRODUÇÃO: WHIRLPOOL S.A.}

Tendo iniciado suas atividades nos Estados Unidos em 1911 como Upton Machine Company, a Whirlpool Corporation opera na América do Sul com as marcas Brastemp, Consul, Whirlpool, Eslabon de Lujo e KitchenAid.

Em 2013, a Whirlpool faturava US\$ 19 bilhões, empregava 69.000 pessoas e possuía 59 unidades espalhadas pelo globo. $\mathrm{Na}$ América do Sul e Central, eram 14.800 colaboradores, espalhados pela sede e diversas unidades, escritórios e centros de distribuição.

Especificamente quanto ao design industrial, a empresa possui estúdios nos Estados Unidos, México, Brasil, Itália, Índia e China, 
totalizando mais de 250 pessoas. No Brasil, são 10 pessoas em Rio Claro (SP) e 35 pessoas em Joinville (SC). A equipe é em sua maioria composta por designers de produto, gráfico e de interface. Mas também participam engenheiros de alimentos, psicólogos e jornalistas.

\section{POSICIONAMENTO FILOSÓFICO}

Se por um lado o mundo em mudança é uma constante, por outro duas abordagens desde há muito tempo são fundamentais para nortear o posicionamento da área de design da Whirlpool Eletrodomésticos.

A primeira trata da proposta de Platão quanto às arenas da sociedade, a saber:

1. A verdade, isto é, a visão cognitiva e objetiva ou perspectiva positivista, dominante na ciência;

2. O bem, ou seja, a visão ética normativa ou a perspectiva moral, que é dominante nas organizações espirituais ou judiciárias e;

3. O belo, isto é, a visão expressiva ou impressionista, também entendida como a perspectiva estética, dominante nas artes.

O campo da ciência organizacional tem, tradicionalmente, colocado toda ênfase na primeira perspectiva, como, por exemplo, na administração científica, na tomada de decisão racional e na assertiva de que medir é saber. Adicionalmente, a perspectiva moral tem cada vez mais relevância, na forma do gerenciamento da qualidade, da sustentabilidade (pessoas, planeta e lucro), da cidadania corporativa e da ética. Entretanto, as pessoas procuram pelo belo tão intensamente como buscam métodos instrumentais e moralmente aceitáveis. Como consequência, a compreensão da lógica interna das teorias organizacionais, assim como de sua efetividade e impacto, deve ser ampliada para se tomar a dimensão estética em consideração 
(AKKERMANS; LAMMERS; WEGGEMAN, 2004). As corporações aprenderam que produzir com qualidade e agir eticamente não são mais suficientes para garantir a competitividade. E é o design que, além de trazer todo o conteúdo da estética para a corporação, deve também ser capaz de integrá-lo à estrutura existente.

A segunda abordagem está relacionada ao conceito grego de conhecimento, que era diferente da compreensão atual. Aristóteles tentou sistematizá-lo e, de maneira geral, distinguiu três diferentes competências, que se relacionam e interagem com três práticas do conhecimento, formando pares. É importante manter em mente a ênfase na prática como parte integrante do conhecimento (JOHANSSON; SVENGREN, 2004).

No primeiro par, episteme era a competência que consistia na criação do conhecimento sem motivo anterior, conhecimento por si só, isto é, conhecimento desinteressado. A essa competência correspondia a prática da teoria. A teoria pressupunha a episteme e por meio de sua execução era desenvolvida.

Havia o segundo tipo de conhecimento, representado por phronesis e práxis. Phronesis significava a capacidade ou competência da sabedoria prática e práxis era o processo de colocar esta competência em ação. Phronesis também pode ser descrito como a capacidade de fazer julgamentos éticos, e práxis seria o processo pelo qual essa capacidade é expressa em ação. Por meio da interação circular entre phronesis e práxis, ambos se desenvolvem como elemento-chave da sociedade. Essa forma de conhecimento reflete-se na boa cidadania.

A terceira forma de conhecimento era chamada techne e poiesis. Techne era a competência e a capacidade de produtivamente criar coisas. A essa competência criativa correspondia a poiesis, o processo em si de criar as coisas. 
A palavra tecnologia deriva, etimologicamente, do grego techne que incluía dois aspectos que estavam intrinsecamente ligados: a habilidade do trabalho e a arte, pois a ideia da produção estética sempre estava associada ao trabalho manual dos artesãos de então.

O termo techne, portanto, tinha um sentido diferente do atual e estava conectado à criação das coisas, sempre considerando o que hoje se entende como um somatório de arte e técnica. É nesse contexto que o design se insere, não sendo propriamente arte nem tecnologia. Ao transitar entre um e outro, traz novos componentes às corporações: o belo, a estética, a experiência. $O$ design deve então ter uma postura mediadora, trazendo a perspectiva da arte para a corporação, mas também a equilibrando com outros fatores, como tecnologia, mercado, capacitações fabris e de suprimentos, por exemplo.

A inserção da arte, por meio do design industrial, no contexto corporativo visa trazer maior competitividade. Abordar as pessoas, cada vez mais dispersas e com maior acesso à informação, só será possível se elas se sentirem únicas, se sentirem que determinada marca pensou em cada uma delas, respeitando-a na sua individualidade. $E$, por seu lado, a marca em si deve transmitir sua aura de unicidade, de peculiaridade. Afinal, nosso cérebro foi projetado para identificar o que é único, diferente, exclusivo.

A construção dessa individualidade se dá, entre diversos fatores, por meio dos produtos com os quais as pessoas se cercam. Entretanto, mais que os produtos, as pessoas compram os seus significados. Este último, no reino corporativo, é domínio do design industrial.

Um iPod, por exemplo, além de um tocador de música, tem em si mesmo a representação da individualidade. A coleção de músicas de alguém, suas preferências e estilos estão todos guardados ali. Dividir 
uma playlist é um grande movimento no sentido de compartilhar essa individualidade, de compartilhar algo íntimo com outra pessoa.

Em outro exemplo, como as motocicletas Harley Davidson e BMW, produtos similares têm significados totalmente diferentes. Enquanto as primeiras representam liberdade e até transgressão, as segundas remetem a conforto e tecnologia.

Um sorvete da marca Häagen-Daaz, com seu nome exótico, mas de origem americana, nos traz a imagem de indulgência, um exagero a se presentear.

Em comum esses exemplos têm o fato de liderarem suas indústrias e de serem notórios na mente de consumidores no mundo todo. Não é uma coincidência.

Essa é uma proeza no mundo dos negócios extremamente difícil de realizar, e quanto mais ortodoxos os executivos, mais distantes da resposta a empresa se encontra. Afinal, como vender o café, que custa $R \$ 400,00$ a saca de $60 \mathrm{~kg}$ e que é vendido a $R \$ 9,00$ o pacote de $500 \mathrm{~g}$ no supermercado, por mais de $\mathrm{R} \$ 300,00$ o quilo? Simples, invente um novo negócio chamado café em cápsulas, ou Nespresso.

Cabe ao design criar produtos que despertem no consumidor emoções e memórias para promover o desejo por estes mesmos produtos, não apenas pelo seu aspecto ou utilidade, mas por conter propriedades cada vez mais intangíveis, que proponham uma experiência. É nesse sentido que o design se aproxima da arte.

Em outras palavras, em um exemplo simples, é preciso competir com Fernando de Noronha. Afinal, as pessoas têm preferido viver uma experiência gratificante, que lhes impregna os sentidos e que permanecerá na memória, a comprar um eletrodoméstico. 


\section{POSICIONAMENTO ESTRATÉGICO}

A área de Design da Whirlpool entende que é preciso ser importante para as pessoas. É preciso causar um impacto positivo, trazendo o conteúdo da arte e da estética para as corporações. É esse nível de experiência que conecta as pessoas com as marcas e torna a função design imprescindível.

Para tal, converte sua postura filosófica e a organiza no seu posicionamento estratégico, que tem cinco perspectivas:

1. Surpreender as pessoas no momento da compra e no uso cotidiano, buscando uma profunda compreensão dos direcionadores da satisfação em ambas as esferas;

2. Criar produtos e soluções com os quais as pessoas se identifiquem, na sua forma, na sua função, na experiência que provoca, no seu significado;

3. Antecipar o futuro, procurando antever os anseios e necessidades das pessoas;

4. Traduzir os aspectos sociológicos para que os produtos sejam compreendidos pelas pessoas e que possam gerar uma conexão positiva;

5. Garantir a tradução correta do posicionamento de cada marca da companhia.

É dessa forma que o Design se assegura de fazer uma contribuição efetiva como disciplina no contexto corporativo, apropriando-se de um conteúdo exclusivamente seu. Assim, passa a ser um direcionador estratégico da inovação e da identidade de marca, conectado ao cerne da companhia. 


\section{INSPIRAÇÃO NÃO, CONHECIMENTO SIM}

Não há bola de cristal. Existe um trabalho sistemático de geração de conhecimento e sensibilização contínua da equipe envolvida no desenvolvimento do design. Todos são estimulados a monitorarem cenários sociais e tecnológicos, gerando apresentações e conclusões. As mais diversas ferramentas da gestão do conhecimento são usadas para se conectar ao consumidor, para conhecê-lo profundamente, e gerar a experiência correta no produto que se desenvolve.

Os designers utilizam os produtos existentes, visitam consumidores, participam da preparação da refeição, do ato de guardar os alimentos depois das compras, acompanham o lavar e estender de roupas. Fotografam casas e pessoas, construindo mapas referenciais que ajudam a desenvolver produtos adequados às necessidades e surpreendentes ao antecipar soluções.

Especialistas também são convidados a participar de eventos: chefes de cozinha, nutricionistas, engenheiros de alimentos e outros profissionais trazem a sua contribuição para a construção de uma ampla base de conhecimento. E não para por aí: especialistas em iluminação e em som, blogueiros, fornecedores, outras indústrias, institutos de pesquisa e internet são fontes também exploradas.

O conhecimento das mais diversas áreas - consumidor, usuário, mercado, marca, tecnologia, tendências, entre outros - é responsável por enriquecer o processo criativo, tanto ao acelerar a geração de alternativas quanto ao ajudar a prover um número maior de alternativas geradas, e também ao assegurar maior assertividade das propostas.

Ao se iniciar o processo de desenvolvimento de produto é preciso primeiro usar do pensamento divergente, isto é, prover a organização com alternativas, opções, caminhos a seguir. Uma 
vez que se criam as escolhas, é possível fazer escolhas - divergir e convergir.

Os workshops criativos são frequentes no Design Whirlpool. A equipe se reúne para debater o conhecimento acumulado, avaliar as premissas do projeto e, em conjunto, gerar uma grande quantidade de opções e soluções para o problema proposto. Não é uma questão de quantidade, somente. Mas sim de quantidade na direção correta.

Esse é um processo iterativo que permite explorar a descoberta, estimular o pensamento criativo e encontrar novas maneiras de abordar os problemas. $\mathrm{E}$, em muitos casos, até mesmo redefinir o problema.

\section{CONCLUSÃO: EXEMPLOS E CASOS}

A seguir se apresentam alguns exemplos da conversão do posicionamento filosófico e estratégico, por meio do conhecimento, em produtos efetivamente lançados no mercado.

Mais que um armário gelado, a geladeira é a central de mensagem da casa, decorada com bilhetes e imãs de tele-entrega. Com base nessa constatação, a equipe de Design começou a buscar soluções que encantassem os consumidores, como, por exemplo, um gravador de voz que pudesse armazenar 3 a 5 mensagens. Entretanto, o melhor conceito surgiu após uma reunião com o fornecedor de tintas, que se dispôs a desenvolver o substrato igual ao de quadro branco, mas com a resistência requerida pelos testes da empresa.

$O$ resultado foi tão inovador e surpreendente que o parceiro responsável pelas canetas assumiu todos os custos do seu desenvolvimento para estar associado a essa ideia e visando a receita recorrente com a venda de novas canetas. 
Uma das dúvidas mais frequentes, especialmente entre usuários iniciantes, é a relação correta entre quantidade de roupa, de sabão e nível de água em lavadoras de roupas. $\mathrm{E}$ a solução pode ser algo tão simples quanto uma marcação numérica que correlacione as funções.

A lavadora de roupas "Nível Fácil" da Consul possui uma escala na parede do cesto, outra no reservatório de sabão e uma terceira no manípulo seletor de nível de água. O usuário deve colocar a quantidade de sabão e definir o nível de água de acordo com o espaço ocupado pela roupa dentro do cesto.

A marca Brastemp, dado o seu reconhecimento, permite explorações em novos segmentos de mercado por meio da criação de produtos pouco convencionais. Uma dessas explorações foi de produtos retrô, aproveitando a tendência mundial nesse sentido. A primeira série de produtos foram refrigeradores compactos lançados em 2005, até hoje disponíveis no mercado.

O sucesso dessa iniciativa deu origem a mais duas linhas de produtos retrô: as geladeiras duplex no frost e os fogões 4 bocas.

A Brastemp também inovou ao lançar, em 2001, uma linha completa de refrigeradores personalizáveis. O consumidor poderia escolher diversos componentes internos, se o produto teria água na porta, tipo de controle eletrônico e ainda uma entre dezenas de cores disponíveis. Eram mais de 14.000 combinações possíveis. Até o ano passado, quando foi descontinuada, a linha personalizável YOU compreendia, além do refrigerador, de um fogão de mesa e de uma lavadora de louças.

Outra iniciativa inovadora (e também de expansão de marca) da Brastemp foi a entrada no mercado de purificadores de água, com a peculiaridade de modelo de negócio por meio de assinatura. Em outras palavras, o produto não é vendido, mas alugado por uma taxa 
mensal. A empresa instala o aparelho e se responsabiliza pela sua manutenção e limpeza periódica. Em caso de desistência, recolhe o produto que tem então sua destinação adequada. Esse produto, e seu modelo de negócio, é um caso de sustentabilidade-alvo de diversos estudos.

Tendo iniciado esse empreendimento em 2006, o filtro de água encontra-se hoje na sua segunda versão, com desenho mais contemporâneo, acionamento eletrônico e inclusão de teclas em relevo "braille".

Em 2013 a marca lançou o primeiro refrigerador com três portas fabricado no Brasil. Sua configuração peculiar, com o freezer na parte inferior e duas portas lado a lado no refrigerador, é complementada por uma interface similar a um tablet. Com conexão sem fio à internet $\mathrm{e}$ aplicativos, o produto possui uma série de funcionalidades, incluindo lista de compras compartilhada pela família.

A marca Consul, por sua vez, vem apresentando inovações ligadas ao dia a dia das pessoas, notadamente com um posicionamento mais jovem. Um exemplo é o forno micro-ondas que possui uma sanduicheira capaz de tostar o pão, deixando-o crocante como no forno tradicional.

Outro exemplo é a cervejeira, um refrigerador com capacidade para até 75 latinhas, que não precisa descongelar, tem visor de vidro e mostrador de temperatura, similar aos modelos encontrados em bares.

E a mais recente inovação vem com a marca Brastemp: uma máquina de bebidas em cápsulas. Trata-se de um purificador que serve água quente, natural, fria e gelada, com ou sem gás. Também é possível inserir cápsulas que permitem a elaboração de mais de 20 sabores, entre chás, café, sucos e refrigerantes. 


\section{REFERÊNCIAS}

AKKERMANS, H. A.; LAMMERS, I.S. ;WEGGEMAN, M. C. D. P. All ye need to know? Aesthetics from a design perspective. Eindhoven Centre for Innovation Studies, eindhoven, 2004.

JOHANSSON, U. ; SKÖLDBERG, K. ; VENGREN, L. Industrial design as a balancing artistry: some reflections upon industrial designer's competence. 2004. Barcelona, European Academy of Design. 
